\title{
Small for gestational age: severity, proportionality and risk of mortality
}

\author{
José Lauro Araujo Ramos*
}

$\mathrm{O}$ low birth weight infants and the perinatal conditions that have repercussions for them, is the attempt to divide (or classify) these newborn infants into groups, in order that certain risks and prognoses can be predicted and, eventually, institute preventive measures.

In common with other groups of children, it has become indispensable to gauge the adequacy of the weight of infants born weighing less than $1,500 \mathrm{~g}$ to their gestational age, bearing in mind neonatal survival, morbidity and the risk of a several different types of sequelae. ${ }^{1,2}$ Among those with extremely low weight and low gestational age it often becomes difficult to know whether it is "immaturity" or "malnutrition" (expressed by fetal growth restriction) that results in the greatest risk of morbidity and reserved prognoses. $^{3}$

The group of preterm infants born with weights of less than $1,500 \mathrm{~g}$ and small for gestational age without doubt require evaluation of physical characteristics that may identify possible "subgroups" and their clinical importance. This is what Grandi et al. are doing in their article published in this issue, ${ }^{4}$ performing a detailed study of the prevalence, severity and proportionality of newborn infants weighing less than $1,500 \mathrm{~g}$ and small for gestational age, according to different degrees of prematurity. They also investigate the risk of mortality according to the condition of small for age and the degree of growth restriction and proportionality.

The risks associated with growth-restricted infants' proportionality is a cause of disagreement in published literature. For perhaps the last 2 decades, the notion of proportionality has been discussed. It was originally valued

* Emeritus professor, Department of Pediatrics, School of Medicine, Universidade de São Paulo (USP), São Paulo, SP, Brazil.

Suggested citation: Ramos JL. Small for gestational age: severity, proportionality and risk of mortality. J Pediatr (Rio J). 2005;81:187-8. by authors such as Villar \& Belizan, 5 then its basic principles were questioned by authors like Kramer et al., ${ }^{6}$ although this author did accept the possibility of proportionality split between symmetrical and asymmetrical types may exist, primarily among the populations of less developed countries.

The results observed by Grandi et al. ${ }^{4}$ reveal an elevated rate of small for gestational age infants in the study group ( $30.1 \%$ below the 10 th percentile and $13.1 \%$ below the 3 rd percentile) and elevated mortality when the condition of small was severe (according to the fetal growth ratio (FGR) and, it is worth pointing out, irrespective of etiology.

According to their ponderal index data, the most common type of growth restriction was symmetrical, which the literature considers to be more severe and generally associated with harmful agents impacting from very early pregnancy onwards; an important finding of this research bearing in mind that chromosomopathies and lethal malformations were excluded from the sample. Another finding worthy of emphasis is the fact that no relation was observed between proportionality and degree of prematurity, which possibly gives weight to the hypothesis that proportionality can also be described for appropriately grown newborn infants. ${ }^{6}$

The proportion of asymmetric restriction increased as the severity of growth restriction increased, as measured by FGR, approaching the initial interpretation offered by Kramer et al. ${ }^{6}$ for this type of restriction. In this study, however, the condition of asymmetrical restriction added little risk to that already conferred by the severity of growth restriction.

The great predominance of symmetrical restriction is noteworthy in this research, diverging from the $20 \%$ cited by Kliegman. ${ }^{7}$ The classical notion that these restrictions are more severe over the long term prognosis is an immediate concern. It should be noted that the absence of bimodality and the low prevalence of $z$-score $<-1$ in the study population, another important contribution made by the study, is evidence against the existence of two distinct groups of growth restriction (symmetrical versus asymmetrical) even among subsets with the most intense 
restriction. These results, therefore, diverge from a part of published literature, ${ }^{5}$ and may possibly contribute to the theory that there is a "continuum" from "symmetrical" to "asymmetrical" and that this is maybe not exclusive to growth restricted infants.

The concern provoked by "symmetrical" restriction is probably due to the fact that in this group cephalic growth is not "exempt", which seems to occur with "asymmetrical". The most marked examples of prejudiced cerebral growth is to be seen among chromosomopathies (excluded from this study) and transplacental infections. The head circumference figures for the infants in this study could possibly be valuable data. This is perhaps one of the most useful parameters for prognosis, 8 rather than "proportionality" which only deals with weight and length. The link between maternal hypertension and asymmetric restricted growth confirms what is generally accepted in the literature. ${ }^{7}$ Emphasis should be given to the mortality figures, which are more than double for infants born weighing less than $1,500 \mathrm{~g}$ and small for gestational age or with more severe restriction. Furthermore, there was no association between mortality and specific neonatal pathology, a finding that is perhaps unexpected, while mortality and lack of prenatal control were associated. The authors interpret this last finding in a manner that, one might speculate, could be applied to other parts of the continent. ${ }^{1}$

One more important approach is the study of the prevalence of small for gestational age and its severity according to that age, a variable that is not often provided in the literature, despite its potential importance to the understanding of the relationship between maturity and growth at the end of pregnancy.

It is worth emphasizing the relation described between FGR and the risk of neonatal mortality.

Undoubtedly, reading this article will provoke certain questions, for example: what influence does maternal stature have on the "symmetry" of growth as mentioned by the authors in their Discussion and, with relation to the minor influence of adolescent motherhood on fetal growth, could this be because the ages of these mothers were distributed close to 18 years?

This research by Grandi et al. ${ }^{4}$ and the multicenter group provides a series of results that were lacking and is an effective contribution to areas that were relatively deprived of study. The study design without doubt should become a reference for future studies in the same field.

\section{References}

1. Leone CR, Sadeck LS, Vaz FA, Almeida MF, Draque CM, Guinsburg $R$, et al. Brazilian Neonatal Research Network (BNRN): very low birth weight infant (VLBW) infant morbidity and mortality. Pediatr Res. 2001;49:405A.

2. Ornelas SL, Xavier CC, Colosimo E. Crescimento de recémnascidos pré-termo pequenos para a idade gestacional. J Pediatr (Rio J). 2002;78:230-6.

3. Gutbrod T. Effects of gestation and birth weight on the growth and development of very low birth weight small for gestational age infants: a matched-group comparison. Arch Dis Child Fetal Neonatal Ed. 2000;82:208-14.

4. Grandi C, Tapia JL, Marshall G, Grupo Colaborativo NEOCOSUR. Evaluación de la severidad, proporcionalidad y riesgo de muerte de recién nacidos de muy bajo peso com restricción del crecimiento fetal. Análisis multicéntrico Sudamericano. J Pediatr (Rio J). 2005;81:198-204.

5. Villar J, Belizan JM. The timing factor in the pathophysiology of the intrauterine growth retardation syndrome. Obstet Gynecol Surv. 1982;37:499-508.

6. Kramer MS, McLean FH, Olivier M, Willis D, Usher RH. Body proportionality and head and length "sparing" in growth-retarded neonates: a critical reappraisal. Pediatrics. 1989;84:717-23.

7. Kliegman RM. Intrauterine growth retardation. In: Fanaroff $A A$, Martin RI, editors. Neonatal-perinatal medicine. Diseases of the fetus and infant. 6th ed. Saint Louis: Mosby; 1997. p. 203-40.

8. Hack M, Breslau N, Weissman B, Aram D, Klein N, Borawski E. Effect of very low birth weight and head size on cognitive abilities at selected age. N Engl J Med. 1991;325:231-7. 